Trabajos de Prehistoria

45, 1988, pp. 289-304

\title{
LA SERIE DE SELLOS DE MADERA PROCEDENTES DE GALDAR, GRAN CANARIA
}

\author{
POR \\ CELSO MARTIN DE GUZMAN (")
}

\begin{abstract}
RESUMEN Este tipo especial de sellos de madera son conocidos en la isla de Gran Canaria con el nombre «pintaderan. De acuerdo con la hipótesis general pertenecían a esquemas o marcas de propietarios e implicarían una aristocracia ganadera y un campesinado diferenciado. Es altamente reminiscente de las distinciones de clase tan agudamente dibujadas entre los antiguos habitantes de la ciudad de Gáldar. Estos nobles trataron de preservar la línea pura por medio de la práctica de la endogamia. En cualquier caso, lo más importante de este estudio es quizá la posibilidad de contrastes entre el análisis arqueológico y el método etnoarqueológico.
\end{abstract}

\begin{abstract}
Pintaderas are a special type of wooden stamp from the Canary Islands. They are generally hypothesized to be owner's marks. This implies the existence of a flockowning aristocracy and a servile peasantry. This is strinkingly reminiscent of the sharply drawn class distinctions among the ancient inhabitants of the town of Galdar. These nobles attempted to preserve a pure lineage by practising endogamy. In any case, the most interesting aspect of this study is perhaps the possibility of drawing contrasts between conclusions arribed at through archaeological analysis and through ethnoarchaeological methods.
\end{abstract}

Los sellos de madera que se estudian en este artículo, completan el catálogo de estos excepcionales y controvertidos objetos lignarios, conocidos y documentados en la isla de Gran Canaria desde el último tercio del siglo XIX, aun cuando su exacta procedencia y circunstancias de los hallazgos no hayan sido convenientemente registradas para su mejor valoración arqueológica. Las piezas que se seleccionan en esta ocasión forman un conjunto, bien característico, de 17 unidades que cuenta con la particularidad de tener certificada su procedencia territorial en Gáldar, una de las comarcas arqueológicas más densas de la isla y antigua residencia de sus reyes o guanartemes. A pesar de que dos de ellas no tienen consignada su procedencia, aplicando criterios morfológicos y códigos decorativos de sus marcas, no existe inconveniente apriorístico para incorporarlas a esta misma serie. En igual sentido, la propia materia prima en que están trabajados estos objetos -en general madera semidura - le otorga un nuevo argumento a favor de su discriminación objetiva frente a las clásicas upintaderas" realizadas en barro cocido. Estas últimas han podido ser contextualizadas en las excavaciones de la Cueva Pintada de Gáldar, dentro de unos repertorios perfectamente

(") Profesor Titular de Prehistoria de la Universidad Complutense de Madrid. 
asociados, con cámaras artificiales adornadas con frisos policromos, cerámica pintada con motivos geométricos, además de figuritas antropomorfas y zoomorfas que acompañan a estos sellos de arcilla. Sin embargo, la difícil situación cronológica de este horizonte cultural, de evidentes y bien dibujadas resonancias mediterráneas, y que hemos denominado Cultura de la Cueva Pintada, no encuentra una explicación satisfactoria en el momento de establecer las correlaciones, no sólo con las restantes culturas insulares, sino con sus vecinas más próximas del litoral atlántico marroquí o del Africa mediterránea. La "cuestión diacrónica" de la arqueología canaria, carente de periodizaciones pertinentes y de sus correspondientes secuencias culturales, sigue siendo la gran asignatura pendiente de la investigación arqueológica. Sin embargo, no cabe duda del vigor y éxito que logra este grupo cultural de Gáldar, esplendorosamente vigente hasta el mismo momento del contacto con los europeos medievales. Estos dan cuenta de una sociedad compleja que ha desarrollado, con más o menos estabilidad, una organización institucional de carácter proto-estatal bajo el modelo de una jefatura monárquica y una clara diferencia de clanes y demarcaciones étnicas. Extremos éstos de la adscripción territorial y al linaje que no deben olvidarse en el momento en que se quiera comprender el código de señales de estos sellos patrimoniales, capaces de indicar relaciones de pertenencia o de vinculación.

Sin necesidad de volver sobre los primeros intentos de interpretación y valoración (Martín de Guzmán, 1984 y Onrubia, 1986), entre los antecedentes bibliográficos que hacen mención a estos cuños de madera, habría que indicar a Pérez de Barradas quien, de modo sucinto, los incorporó a su catálogo de materiales; estudiados por él mismo en el Museo Canario con motivo de su estancia en el Archipiélago (Pérez de Barradas, 1944). Con posterioridad, Alcina vuelve a tocar el tema de las "pintaderas" sin descender a un tratamiento específico de estos sellos de Gáldar (Alcina Franch, 1956).

En nuestra opinión, tanto por el hecho objetivo de su materia prima como por su procedencia y contextualización cultural, estas piezas demandan un análisis más detallado que nos permita plantear algunas cuestiones de interés de la arqueología canaria más allá de la simple clasificación tipológica.

\section{DOCUMENTACION AROUEOLOGICA}

El exacto contexto de estos enigmáticos objetos no siempre ha podido ser rigurosamente determinado, al igual que muchas cuestiones de la arqueología canaria debido a la imperfección de los planteamientos y procedimiento empleados en los trabajos de campo con anterioridad al año 70. Pero si lamentable es este "hiatus» en la información de las excavaciones no menos desalentador, y sintomático, es el hecho mismo de que en las Crónicas (Morales Padrón, 1978) no se haga alusión alguna a estos sellos o marcas, de arcilla o madera, máxime si se considera la indicación de otros detalles de menor entidad como las tausas, pequeños cortadores obtenidos de la talla de la obsidiana. Es verdad que tampoco se hace referencia expresa a las figuritas y representaciones zoomorfas y antropomorfas de las que la arqueologia ha recuperado un nutrido e interesante repertorio. Esta falta de noticias y la *novedad" que supuso su aparición en la arqueología insular del XIX, llevó al mismo Verneau a dudar de su autenticidad indígena y a lanzar la hipótesis de su probable importación. Sobre su misma denominación, por evidente analogía con los sellos de panadero, el nombre de "pintadera" fue otorgado por los campesinos cuando se les enseñaban estos objetos, nombre consagrado por la literatura arqueológica. Otra información habla de "sellos de los reyes", extremo éste que ha contado con valoraciones diversas. De cualquier modo, es a partir de 1880 cuando ya se empieza a polemizar sobre estas "pintaderas", nombre que, según Verneau, le fue dado por los labriegos de Santa Lucía de Tirajana (Verneau, 1983: 1).

Aun cuando se hân podido documentar ejemplares aislados en otras islas (La Palma, Fuerteven- 
tura y Lanzarote), éstos se distancian, tipológicamente, de las series y los códigos decorativos grancanarios, muy bien reglamentados, y no se han ofrecido en una asociación arqueológica similar a la de la Cultura de la Cueva Pintada. Lo cierto es que si no únicas las piezas de Gran Canaria, parecen excepcionales y conforman uno de los atributos más relevantes y sofisticados del repertorio material de las distintas aportaciones $u$ "horizontes* culturales que parecen imbricarse en un proceso de sincretismo, dentro de un universo de formas que opera en Gran Canaria a lo largo de más de 1.500 años.

Tampoco hay que descartar la posibilidad de la presencia de naturales de Gran Canaria en otras islas, bien en un hipotético contacto prehistórico, o más probable a tenor de los movimientos migratorios impuestos por las deportaciones y trasvases de población, como consecuencia de la Conquista de las islas de realengo (1478-1496). Pero las piezas encontradas fuera de Gran Canaria, en contextos arqueológicos más o menos fiables, nada tienen que ver por su formulación decorativa, técnica y ambiente cultural, con las clásicas «pintaderas» grancanarias.

Para ilustrar un poco el origen de este confusionismo, del que fue víctima el propio Verneau llevado de la autoridad de su paisano Sabino Berthelot, vale la pena recordar cómo las pintaderas de la Colección Lebrun que Berthelot hacía proceder de la localidad tinerfeña de Güimar y, por lo tanto, pertenecientes a la «cultura guanchew, en realidad, tal y como se preocupó en aclarar Diego Ripoche, procedían de la villa de Gáldar, en la isla de Gran Canaria.

Recientes excavaciones han certificado en contexto estos sellos en asociación con la Cultura de las Cuevas (complejo de Acusa), y con la Cultura de los Túmulos (La Aldea y Valle de Guayedra han aportado series largas de sellos de arcilla asociados a estructuras arquitecturales de paredes rectas). Parece mucho más significativo, el contexto cerrado, dentro del recinto ceremonial, de la Cueva Pintada. En efecto, el vaciado llevado a cabo, en 1970, con motivo de la restauración y ampliación del acceso a la cámara principal de las pinturas, puso de manifiesto la contextualización de estos sellos en un rico complejo artificialmente excavado, con cerámicas profusamente pintadas con temas geométricos, motivos correspondientes al mismo discurso decorativo de los emblemas de los paramentos; a su vez con fuertes analogías con el registro rectilíneo de las improntas de los sellos. La ausencia de estas piezas en otro registro tan bien definido como lo es la Cultura de Tenerife, además de su alto índice denotativo, refuerza la hipótesis de un origen diferenciado para ambos contextos, además de la lógica diferenciación impuesta por el aislamiento, las distintas estrategias de adaptación, y la deriva propia de toda cultura o grupo cultural sometido al hermetismo.

Sin apurar trasnochados difusionismos lo cierto es que la fuerte asociación que para Gran Canaria significa la cadena de configuración cultural cuevas artificiales decoradas + cerámica pintada con temas geométricos + figurillas de arcilla, esquemáticas y figurativas + sellos de arcilla con improntas geométricas, contiene todos los elementos asociativos y característicos, más que suficientes para definir un horizonte cultural con personalidad propia. Horizonte bien distinto y diferenciado al de la Cultura de Tenerife, y donde otros rasgos sobresalientes como los collares de cuentas segmentadas, los procedimientos rituales o las técnicas funerarias de sus envolturas y mirlados le sitúan en otro diámetro; aun cuando el tratamiento de los difuntos y la presencia de fardos sea una de las dos o tres formas utilizadas en las artes de la funeraria grancanaria.

Esta argumentación arqueológica, expresada anteriormente, se justifica para llamar igualmente la atención sobre otra evidencia negativa de gran interés en el momento de las interpretaciones. Hasta el momento no se ha podido documentar ninguna "pintadera" en los ajuares funerarios de los habitantes prehistóricos de Gran Canaria como elemento equivalente a los segmented.bead que acompañan a los cadáveres y momias guanches de Tenerife.

La mayor parte de los sellos pintaderas proceden de áreas de ocupación activa como son los poblados, o agrupaciones de estructuras artificiales, tanto en el interior como fuera de las viviendas. Tal es el caso de Majada de Altabaca, en Guayedra, con seis ejemplares; el poblado de la Costa de Gáldar, Agưimes o Telde, con el «record» de más de 25 ejemplares para el yacimiento de Los Caserones, en La Aldea, en el sector oeste de la isla, donde, en un principio, se creyó que no se encontrarían estas piezas. 
Una de las primeras noticias sobre circunstancias de los hallazgos se debe a Grau-Bassas, quien, al referirse a los hallazgos de Agüimes, no extrae ninguna valoración arqueológica de interés: «Nada noté en el sitio del hallazgo que pudiera revelar que en aquel punto hubiese existido habitación ni albergue de los antiguos, ni el terreno parece a propósito para construcciones, ni en las inmediaciones se descubre vestigio alguno de cuevas" (Grau-Bassas, 1881: 357).

Paralela a la documentación arqueológica surge la cuestión de la cronologia de estas piezas (y del complejo cultural que ellas expresan). Para la isla de Gran Canaria hemos propuesto un doble esquema de articulación temporal/cultural para los, al menos, tres horizontes culturales que se detectan en el nivel estructural de su registro arqueológico pseudo-sincrónico. Los al menos 2000 ó 2500 últimos años de la prehistoria reciente de la isla en un segmento cronológico que iría desde la primera mitad del I Milenio hasta el 1500 d.C., necesitan, en buena lógica, de una sucesión en el tiempo, en el mismo sentido en que se habla de Bronce Antiguo, Final, Primera Edad del Hierro o Campos de Urnas. Esta periodización, siguiendo el modelo clásico tripartito y sucesivo, se estructuraría en, al menos, tres grandes períodos, por parte, lógicos e inevitables desde una óptica estrictamente secuencial y de "duración histórica»; de tiempo real, de esos 2000 años, ahora planos, sin relieves, y entendidos como una agobiante y amalgamada sincronía. La propuesta, una vez más explicitada, sería siguiendo el modelo evolucionista-cultural, así:

\section{Periodo Inicial: Para los primeros asentamientos hasta su adaptación.}

II. Periodo Medio: Para el momento "formativo", y donde después de superada la adaptación y ensayadas las distintas estrategias productivas se asiste a una progresiva insularización de los modelos iniciales, implantados en el periodo inicial.

III. Periodo Final: Que tiene su conclusión con la presencia histórica europea, en concreto bajo medieval y que, en cifras redondas, podría situarse cerca de 1500 d.C. Aquí se detectarían los sincretismos y las supervivencias, y se cuenta con la posibilidad de un registro etnohistórico, de más de 200 años de información y que habrá que valorar en sus justos términos.

Junto a esta periodización elemental, o lectura organizada del problema desde su perspectiva diacrónica, no se puede obviar la presencia de *ambientes", «horizontes" o grupos culturales" diferenciados, y que en el Perido Final se nos ofrecen amalgamados bajo mimetismos originales y supervivencias anacrónicas, en el marco de una estructura claramente proto-estatal, que conforma lo que hemos denominado guanartemato. Por ello mismo sería ingenuo obviar el proceso interno acontecido en los dos últimos milenios de prehistoria insular reciente; los cambios operados en su sociedad, las oscilaciones derivadas de sus perceptibles ciclos cortos climáticos, con la constante y recurrente incidencia de los «años secos"; las diversas estrategias de ocupación y colonización del territorio, la carga demográfica y sus correctivos institucionalizados. Todo este planteamiento de investigación que apenas, tímidamente, se ha iniciado y que da a la arqueología insular una posibilidad paradigmática. La arqueología que se practica en Canarias adolece de estas rémoras y no se ha decidido, plenamente, por un modelo más rendidor, prefiriendo el camino más corto (y más fácil) de considerar el universo cultural insular sin perspectivas ni relieves, como algo liso y atemporal, heteróclito y abigarrado, y donde todo pareciera corresponder a un solo y único período, y a una sola cultura. Frente a esta desolada planicie hemos propuesto (1978), a partir del registro de cultura material, al menos, tres horizontes:

1. Horizonte de las Cuevas: Entendido en equivalencia relativa con la "Cultura de Tenerife", y donde quedarian integrados los elementos neolíticos de sustrato, también denominados "pancanarios". Se trata de cuevas naturales, directamente aprovechadas y que conforman el hábitat o residencia dominante. La gran dicotomía, que impide una homologación total, deriva de los distintos repertorios 
cerámicos; pero, en líneas generales, se trata de cerámicas lisas, con decoraciones parciales, incisas e impresas y en ningún caso, almagradas o pintadas con motivos geométricos.

2. Horizonte de los Túmulos: Entendido como una configuración cultural mucho más compleja, en asociación, al menos en gran parte de la secuencia, con las casas de paredes rectas, hechas en piedra seca, con algunos sillares intervenidos o semilabrados. Su expresión más espléndida se visualiza en Gran Canaria, particularmente en los asentamientos próximos a la costa. Este «horizonten, con amplias asimilaciones de origen noroccidental africano y mediterráneo, está prácticamente ausente en el grupo occidental de las islas. En este sentido Gran Canaria se aleja de Tenerife y se aproxima a los modelos residenciales de Fuerteventura, donde estos poblados al aire libre, con construcciones artificiales de piedra, están magnificamente representados.

3. Horizonte o «Cultura de la Cueva Pintadas: Entendido como complejo en clara asociación arqueológica, fuertemente denotativo, característico de Gran Canaria y sin evidentes o manifiestas equivalencias en ninguna de las otras islas del Archipiélago. Sus rasgos, de marcados acentos mediterráneos, traen ecos de las culturas neolíticas tempranas del círculo del Egeo y mundo danubiano, y conecta con sus símiles morfológicos de Liguria y Mediterráneo Central. Se trata de un grupo que podriamos llamar de raigambre oriental; en este sentido el menos africano, aun cuando en determinados elementos conecta con los bereberes del Africa mediterránea (Argelia Oriental y Tunicia), postulándose más que una relación derivada la de un origen común para ambos círculos culturales. En nuestra opinión, aquí está el nudo gordiano de la arqueología canaria pues aún no se ha determinado el momento de entrada de estos portadores culturales y su grado de implicación e influencia en los horizontes descritos anteriormente. Se indica, igualmente, que los sellos pintaderas se corresponden, sin lugar a dudas, a esta cultura u horizonte.

El orden con que se han determinado los horizontes no prejuzga su real posición diacrónica en la secuencia general, donde pueden intervenir o incorporarse cada uno de ellos a partir de dos posibilidades: a) Que el sincretismo venga ya dado desde los primeros fundadores, en una primera y única arribada a Gran Canaria (klos protocanarios»). Hipótesis difícil de sustentar puesto que en ninguna otra isla hay nada semejante ni siquiera en todo el noroccidente de Africa, que nosotros conozcamos. b) Que el sincretismo sea el resultado lógico de un proceso de maduración y adaptación de la sociedad prehistórica canaria, al que no hay que descontar estímulos externos (aunque esporádicos, estimulantes) que se evidencian en la complejidad de la Cultura Cueva Pintada, cuya posición cronológica también pudo ser la inicial en esta secuencia general pero que por su mejor equipo de bienes perdura y, en cierta medida, tiñe y se impone sobre los otros grupos.

\section{FUNCIONALIDAD Y ETNO-AROUEOLOGIA}

Sobre el uso o funcionalidad de los sellos tampoco ha habido unanimidad entre los autores que han tratado el tema. Chil y Naranjo, en el Congreso de Nantes de 1875, fue uno de los primeros que atribuyó a éstos un valor mágico, entendiendo así su carácter de amuletos. Esta misma interpretación fue aceptada por Millares (Millares Torres, 1893), reparando en el detalle de los mangos perforados que, en su opinión, tendrían por objeto que estos talismanes fuesen prendidos del cuello.

La denominación popular de "pintaderas" por su similitud con los sellos para "pintar" el pan, "pan pintado", (práctica usual en los hornos colectivos para poder identificar, por sus marcas, la pertenencia de cada uno o familia), llevó a estos eruditos a relacionar, directamente, la funcionalidad de la pieza con su homóloga castellana (Verneau, 1883: 12-13). 
Verneau fue uno de los primeros en considerar estos sellos como improntas tegumentarias con las que los antiguos canarios adornarian su rostro o destacadas partes de su cuerpo (Verneau, 1883: 13). Venía en apoyo de esta hipótesis un dato confuso de Le Canarien (1402), donde se hacía referencia a escarificaciones, tatuajes o labrados de la piel con caprichos geométricos. Pero, claro está, sería muy exagerado confundir ambas técnicas de intervención somática. También se señalaba en favor de esta hipótesis de pintarse la referencia de Cadamosto: «tanto los hombres como las mujeres tenían la costumbre de pintarse el cuerpo con jugo de hierba de diversos colores, verde, rojo y amarillow (Cadamosto, 1895: 111). Procedimiento más próximo al de embadurnarse la piel que sellársela delicadamente con improntas de sellos realizados ad hoc. (1).

El dato empírico de que algunos de estos sellos, procedentes de hallazgos no siempre bien certificados, conservaban residuos de ocre (como era el caso de algunas piezas de la Colección Maffiotte), decidió a Verneau a aplicar la prueba experimental con impregnaciones estampadas directamente sobre la piel humana. Según da cuenta el mismo Verneau: «... los dibujos más delicados aparecieron con toda precisión. Habiéndolos dejado secar algún tiempo sobre la piel fue necesario frotarla luego repetidas veces al querer borrarlas de ella, pues el agua corriente no bastaba para conseguirlon (Verneau, 1883: 17).

Diego Ripoche, animado por las ideas de su tiempo, va a ser el pionero del peligroso camino del difusionismo cultural a ultranza (hiperdifusionismo), para explicar fenómenos aislados y descontextualizados, recurriendo a la ley de la analogía (criterio de forma). A partir del análisis comparativo no tiene reparos en establecer orígenes y funciones a la vista de piezas semejantes documentadas en yacimientos tan alejados de Canarias (Océano por medio), como Assinia, México, Colombia, Yucatán y Venezuela. Argumentaba Ripoche, entre otras razones, que Diego de Landa en su Relación de cosas del Yucatan, recoge el dato de cómo los nativos pintaban el cuerpo con pintura roja mezclada con goma. No quedaba bien explícito el uso de los sellos, pues una cosa es impregnarse el cuerpo y otra muy distinta adornarlo con marcas controladas (Ripoche, 1902: 1 y ss.).

Al margen de su teoría difusionista, en líneas generales, tampoco Ripoche se apartaba de las interpretaciones de Verneau, y a grandes rasgos venía a sustentar lo que sigue:

- Que las pintaderas habían sido encontradas en lugares donde los canarios tenían por costumbre pintarse la piel, como era el caso de Gran Canaria.

- Que en algunos de sus ejemplares se podian observar residuos de colorantes.

- Que algunos autores coetáneos hablan de su uso entre los naturales isleños para pintarse la piel.

- Que piezas similares han perdurado hasta la misma Edad Media en ciertas culturas, que también las han utilizado para pintarse. En este registro acudía al símil americano.

Cuando en 1925 Hooton se ocupa de la interpretación de estos sellos, intenta retrotraerse a los orígenes neolíticos y calcolíticos de tales piezas, documentadas en contextos culturales del Mediterráneo oriental y central. Justificaba, vía difusionismo, su presencia en Africa del Norte y Canarias, sin descontar, desde el Viejo Mundo, su arribada a América: «The occurence of pintaderas in North Africa or in the Iberian peninsula seems questionable and the distribution of these objets makes it probable that they are a feature of a Balkan culture. Of course it is conceivable that the Canarians invented pintaderas themselves as the Indians of the Valley of Mexico may have done but it is more likely that use in the island was due to trade with, or colonization, by Mediterranean seafares". (Hooton, 1925: 59).

Por su parte, los estudios de Pérez de Barradas (1939 y 1944), llaman la atención sobre la similitud decorativa de determinados vasos pintados y las pintaderas, con insistencia en las líneas quebradas, los círculos, los dameros y los triángulos elegantemente dispuestos, con un ritmo y órden estético. Pérez de Barradas no dudó en establecer paralelismos con las culturas neolíticas de Liguria (Arene Candide); con los fondos de cabaña de Reggio, y con toda la gran tradición de la cultura danubiana. En este sentido, como en otros de su misma cerámica (idolillos y figuritas

(1) «... pintábanse de muchos colores para la guerra y para bailar las fiestas». López de Gómara, 1552. Cap. CCXXIV, fol. 99. Vid. Martín de Guzmán, 1984: 159. 
zoomorfas) la arqueología grancanaria parece orientarse hacia el Mediterráneo y alejarse de sus vecinos más próximos norteafricanos. Si bien estas fórmulas geometrizantes son comunes entre los bereberes actuales, no han podido documentarse en un contexto arqueológico como la Cultura de la Cueva Pintada, a no ser que se quiera ver en los sellos auresianos un trasunto de los canarios, extremo éste magníficamente precisado en el interesantísimo artículo de Onrubia Pintado, donde quedan sancionadas muchas valoraciones sobre la funcionalidad y analogia de estas piezas (Onrubia Pintado, 1986).

En esta interpretación etnoarqueológica, ya en la década de los 40 , Marcy había introducido novedades de fondo, a partir de sus propias observaciones, y es quien primero llama la atención sobre la funcionalidad de los sellos usados por los montañeses de Aurés, alejándose tanto de las interpretaciones ritualistas como de las decorativistas que, hasta entonces, se disputaban la supuesta utilización de estos objetos lignarios o cerámicos. Para Marcy estos sellos de madera (siguiendo el modelo auresiano) eran utilizados para precintar los cierres de las celdas de los graneros o agadires. Fue así como se vió, de inmediato, un paralelismo con el conjunto de Cuevas de Valerón, en el norte de Gran Canaria, no lejos de Gáldar, máxime si se reparaba que, aquí, se había encontrado, al menos, un sello de arcilla. Esta correlación abrió una nueva discusión que alcanzó ya no sólo a los sellos, sino a las propias cuevas canarias. Quizá sea revelador para comprender la magnitud institucional de este recinto de la Cuesta de Silva, conocido desde antiguo como "Cuevas de los Canarios" o "Cuevas de Valerón" (nombre este último tomado de uno de los primeros propietarios de después de la Conquista), reflexionar sobre el carácter dual (práctico-mágico) de los graneros entre los tuaba del Aurés. En efecto, la mejor manera de ritualizar un sitio es depositar en él los cadáveres o restos de algún antepasado preponderante, figura principal y común en los linajes y sistemas de parentesco (Faublée-Urbain, 1951: 141). No nos debe, pues, extrañar que en estos recintos aparezcan restos de cadáveres sin ser, necesariamente, una necrópolis específica. Esto puede también explicar las noticias sobre restos de cadáveres en la Cueva Pintada, en las Cuevas de la Huerta de Rey y en el propio complejo de Cuevas de Valerón, yacimientos todos de la misma demarcación prehistórica del guanartemato de Gáldar. Así el valor sagrado y ceremonial de la Cueva Pintada, que servía de «audiencian de los antiguos canarios, podría sustentarse a partir de su carácter de "relicario», o kaltan donde se conserva una suerte de "ara de los fundadores", o héroes primigenios. Las cazoletas que se excavaron, intencionalmente, en su suelo (y a las que los arqueólogos no han encontrado una satisfactoria explicación), cumplirían el doble papel de pozos de ofrendas y de urna para conservar, previamente desarticulada la osamenta de los notables. Hay, sin lugar, a dudas, una sobrecarga semántica del espacio. Una lectura similar podría hacerse extensiva a Cuevas de Valerón, también como lugar de culto (santuario ocasional) habida cuenta de los restos de los antepasados allí conservados; no sólo servirían como guardianes para atemorizar a los furtivos ladrones que se acercaran a este silo comunal, sino que quedaban metafóricamente relacionados con los cultos de la fertilidad-resurrección, inherentes a los rituales agrícolas. En este granero colectivo, o pósito estatal, se guardarían no los excedentes de producción para los años faltos, sino los granos necesarios para la siembra, sin los cuales sería imposible garantizar el ciclo agrícola y, en consecuencia, la paz social del guanartemato. Estos preciosos granos deberían estar a salvo de cualquier eventualidad, agresión o revuelta, invasión o calamidad. Y una de las obligaciones principales del estado guanartémico sería, precisamente, garantizar por todos los medios (tanto mágicos como coercitivos) esta continuidad de las cosechas, que es lo mismo que la continuidad del orden social. No vemos, entonces, ninguna contradicción en esta ampliación del significado ritual de las Cuevas de Valerón, como granero y lugar sagrado, relacionado con los ceremoniales del grano, las sementeras, la fertilidad-fecundidad. Lo que sí resulta disparatada es la tardía interpretación dada a estas cuevas como convento o cenobio de vírgenes (harimaguadas o maguadas) máxime cuando el gineceo estaba emplazado en las proximidades del Palacio de Gáldar (Martín de Guzmán, 1984: 164).

Para Marcy los sellos estarían destinados a marcar los cierres de arcilla, aun cuando, en nuestra opinión, y como se verá más adelante por otros testimonios etnoarqueológicos, por el principio de 


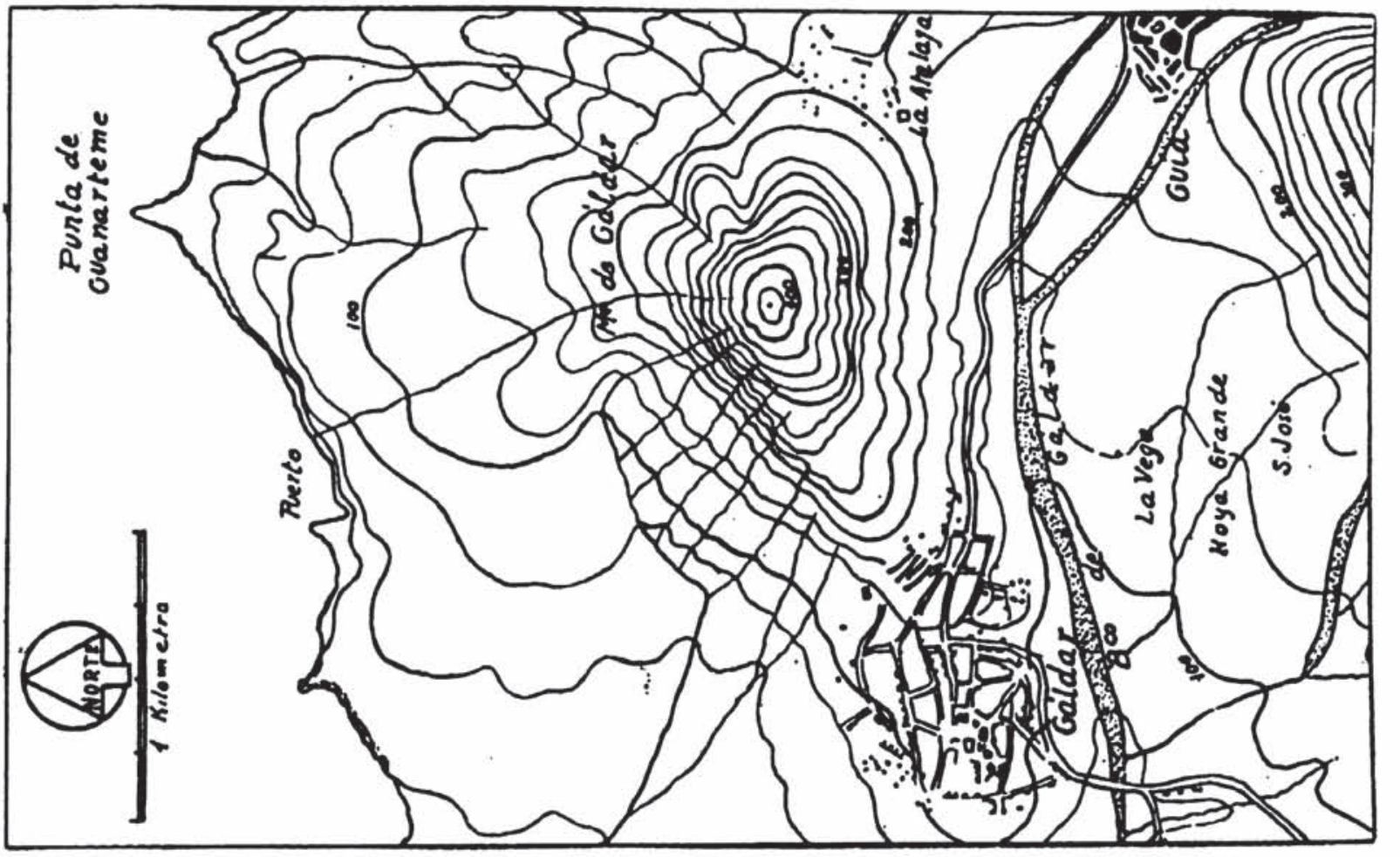

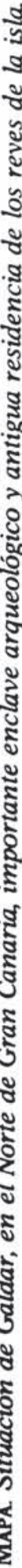


magia contaminante, pueden devenir en instrumentos de manipulación curativa. Según pudo certificar Marcy, el procedimiento es bien sencillo: «Un agujero de pequeñas dimensiones, abierto en el batiente de la puerta, en el puesto usual de la cerradura, permite introducir una cuerda de esparto trenzada por medio de la cual puede sujetarse la puerta a una barra vertical de madera, sólidamente unida al dintel. Una vez anudada la cuerda por el propietario coloca éste sobre el nudo un grueso tampón de arcilla en el que imprime al punto su sello personal" (Marcy, 1942: 120).

Pero no todos los prehistoriadores han encuadrado el problema en esta valoración etnoarqueológica sino que, por el contrario, han preferido hacerlo ajustado a estrictos criterios de periodización morfológica o a velocidades difusionistas. Para Pericot no se pueden interpretar estos sellos sin hacer una referencia a las fases iniciales del neolítico de Siria y Palestina donde ya se documentan, en época temprana, estas extrañas piezas realizadas en piedra. En la fase danubiana II, abundan ya los sellos de arcilla que siguen y repiten su tradición oriental. En una interpretación y valoración del sustrato mediterráneo que, evidentemente, se detecta en Gran Canaria, Pericot consideró que las pintaderas canarias no eran otra cosa que un elemento más de esa gran corriente cultural de origen oriental que a través del Norte de Africa alcanza Canarias en el III milenio (Pericot, 1955: 28). Este mismo criterio difusionista fue utilizado en el trabajo de Alcina quien dice que «...debemos considerar a las "pintaderas" como parte de un fenómeno general de difusión que, partiendo del Próximo Oriente llegaría a morir a América. Nuevamente, pues, Canarias es el lugar de paso que une a Europa con América aún en tiempos prehistóricos" (Alcina Franch, 1956: 102-103).

La ponderación crítica de Serra Ráfols intentó reconciliar posiciones y buscar una salida más razonada a los falsos planteamientos sobre el origen, uso y aplicación de estos tampones decorados. Serra creía que podía haber pintaderas para varios fines; unas para sellar, otras para pintar, otras como amuletos. Ya en este mismo sentido se había expedido Monod a partir de los registros etnoarqueológicos por él conocidos del Africa noroccidental, donde estas piezas, o mejor, sus símiles, no sólo cubrían una función práctica de identificación de propiedad, sino que intervenían en procedimientos de carácter mágico o ritual (Monod, 1944: 267-268).

Un similar carácter de poliuso fue explicado por Balout que habla de las múltiples aplicaciones de estas piezas no sólo para impresiones de color sobre la piel humana sino en cueros, tejidos, barros e incluso tortas o galletas que precisasen ser identificadas. Pero, en todos los casos, tendrian función de "marca" (Balout, 1971: 100-101).

Pellicer al referirse a las pintaderas canarias las correlacionó con los «cigard" de la cultura de Ntereso (Alto Volta), y con sus similares del neolítico de Kintapo (Volta Negro), elementos que quedarían explicados a partir de los influjos del neolítico reciente de tradición sudanesa donde, a nivel formal, se pueden establecer (aunque no siempre justificar) analogías y cadenas taxonómicas (Pellicer, 1974: 156).

En el cuadro de estas relaciones con el Africa Occidental, en Costa de Marfil, ya en plena Africa Negra, entre Comoé y Agueby, el mismo Monod pudo revisar una interesante colección de sellos pintaderas propiedad de M. Bédiat quien a su vez le sirvió de informante trasmitiéndole una interesante información sacada de sus experiencias con los indígenas. Los nativos de esta región emplean estos tampones para imprimir sobre el cuerpo de las mujeres, cuando éstas están de parto, con el fin de propiciar efectos benéficos en contacto con los caracteres y dibujos de influjo mágico, y protector contra hemorragias y otras complicaciones que entraña la crisis somática de la parturienta. Estas prácticas, en los últimos años, han decaído y tan sólo las mujeres ancianas conservan algunos de estos objetos como reliquias. Su decoración, en general, es de tipo geométrico y se ajusta a un código cerrado y tradicional. Cada uno de los signos, o marcas, tiene su nombre y su significado además de su específica propiedad curativa (Monod, 1944: 268-269). Estos mismos sellos también pueden utilizarse para estampar sobre tejidos, quizá con el mismo fin apotropaico, de proteger contra el mal y la muerte. Con esta significación puede entenderse su valor como «sello protector de la muerten, con lo que se podría postular una lectura complementaria de segundo orden.

Volviendo a los sellos grancanarios y a su posible carácter emblemático, como una proto- 
heráldica insular, este argumento cuenta con una serie de elementos institucionales que entran en concomitancia en el momento de las interpretaciones. El proto-estado guanartémico, estaba sostenido por un estamento aristocrático que actuaba como «brazo armadow, formado por un cuerpo nobiliario de 200 caballeros, con prerrogativas y atributos muy bien indicados; como el hecho de llevar el pelo largo y teñido de rubio, frente a los «trasquilados» o villanos (2).

Las marcas heráldicas, los blasones de los linajes, podrian, igualmente, concentrar y monopolizar en esta clase señorial la expresión de unas prácticas rituales propias de su estatuto guerrero (como lo era el ceremonial de la investidura o ascenso al estamento privilegiado). Los sellos, entonces, además de propiciar el triunfo del héroe sobre la muerte y frente a ella, protegía con sus marcas al guerrero y le identificaba frente a los otros (amigos o enemigos). Hay datos sobre este carácter emblemático de las marcas geométricas en las refriegas entre los príncipes canarios Doramas y Bentaguaire en la demarcación de Arguineguin, en el sur de la Isla (3). Las rodelas o escudos pintados (con motivos ajedrezados y lineales), que refieren las Crónicas, conectarían con este mismo discurso y otorgaría a los sellos (igual que a los escudos) un carácter de insignia heráldica, identificadora del clan o linaje (no más de 200 caballeros, agrupados en sus correspondientes sistemas de parentesco). Las fuentes etnohistóricas de Gran Canaria van en este sentido sin lugar a dudas.

En la valoración etnoarqueológica, y en busca de una explicación estructural, la documentación de sellos corporales en la región de Assinia (también en Costa de Marfil), refieren cómo las ancianas guardan en unas talegas una serie de sellos de madera acompañados de dos o tres pequeños vasos y recipientes y de ocho o diez bolsitas con tierras colorantes de distinta procedencia y valoración. Estas arcillas seleccionadas (amarillas, blanquecinas, rojas) se aglutinan con líquidos y hierbas a las que se les conceden propiedades curativas, formando con todo una mezcla pigmentaria. Cuando algún miembro del clan enferma se le aplica el sello impregnado de esta masa ungüenta y colorante, exactamente sobre la zona del cuerpo donde irradia el dolor. Previamente se le ha practicado la oportuna e intensa frotación manual que, en realidad, es la que aminora la dolencia. Lógicamente, si el dolor desaparece o se calma, los personajes que realizan estas prácticas curativas ya se preocuparán de explicar que ha sido la aplicación del sello y los pigmentos sobre el cuerpo quien ha realizado la cura milagrosa. Entre las intervenciones más frecuentes no es raro ver a las jóvenes madres, víctimas de los abscesos mamarios, recurrir a estas prácticas y ofrecer sus pechos adornados de estas marcas producidas por las improntas y los pigmentos curativos. El ceremonial y el preparado, al igual que la custodia de estos sellos, están en manos de ancianas o mujeres mayores, prestigiadas dentro de la comunidad (Monod, 1944).

Una observación paralela y pertinente, realizada con el ajuar que se utiliza en estas intervenciones mágico-curativas puede establecerse con los pequeños recipientes, donde se prepara la masa colorante y se impregnan los̀ cuños para luego aplicarlos sobre el tejido humano. El registro arqueográfico grancanario tiene igualmente documentados estos minivasos o microcerámicas, cuya significación y funcionalidad todavía no ha quedado resuelta satisfactoriamente. Unos han insinuado su uso como simples juguetes infantiles, piezas de entretenimiento (Martín de Guzmán, 1984: 357). Otros han recurrido a la ambigüedad de «elementos votivos». En valle de Guayedra y en Cueva Pintada de Gáldar se han documentado en asociación con sellos de arcilla y el interior de los módulos

(2) «Tienen dos príncipes a los que dan título de rey y de duque; pero todo el gobierno de la isla se halla entre las manos de ciertos caballeros, cuyo número no puede ser menos de ciento ni pasar de doscientos. Cuando cinco o seis de estos caballeros llegan a morir, los demás se reúnen para proceder a la elección de aquellos que deben acupar las plazas vacantes y éstas deben recaer en los hijos de los caballeros, de modo que el número de ciento se halla siempre completo. Estos caballeros son considerados como pertenecientes a la primera nobleza (la más pura) no habiendo jamás contraído alianza alguna con clases inferiores». Azurara, 1451. Vid. Martín de Guzmán, 1984: 140.

(3) *... deste árbol hacían rodelas para su defensa y eran grandes y pintadas de divisas.» Escudero, redacción Cardona, 1639, Cap. XIX, 84. Vid. Martín de Guzmán, 1984: 168.

LLas otras armas son chuzos gruesos con punta del mismo palo, muy lisa y aguda, y arrojada a pulso, que pasaban a un hombre por medio; tenian espadas de palo a modo de montantes, y unas adargas cuadradas y otras redondas y pintadas de almagra y carbón cuarteados y alxedreses; y otras con lanzas largas y puntiagudas.» Escudero, redacción Cardona, 1639. Cap. II, 8. Vid. Martín de Guzmán, 1984: 170. 
habitacionales. Tampoco ha podido establecerse su adscripción al mundo funerario. No parece por lo tanto desacertada la hipótesis de entender su uso como piezas asociadas a los sellos (como lo es hoy el sello y la almohadilla entintada). Quedarian entonces las microcerámicas en relación directa con los sellos pintaderas habida cuenta de que, sin una mezcla preparada, y conservada convenientemente, no podrían obtenerse en seco, las marcas pigmentarias sobre las superficies a las que se aplicaran estos tampones de arcilla cocida, o de madera.

\section{TECNICA}

Queda por determinar y precisar la o las especies arbóreas concretas de la madera utilizada, como materia prima, para la elaboración de estos sellos de madera. Nada se opone a considerarlos como objetos autóctonos máxime si se acepta la disponibilidad de maderas adecuadas para estos fines; maderas semiduras, duraderas y consistentes, previamente endurecidas por procedimientos artificiales de frotación, pulimento y calentamiento de los fustes, seleccionados para realizar las posteriores tareas de labrado y excisión. Especies como el Pinus canariensis (pino canario), Ocotea foetens (til azorica), Persea indica (viñátigo), Apollonia barbujana (barbusano) o Ilex canariensis (acebiño) se registran entre las más frecuentes y consideradas por los antiguos canarios para la fabricación de sus instrumentos, armamentos, entablamentos y objetos lignarios. Gran parte de estas maderas proceden del monte bajo (influenciado por el alisio), el escalón botánico intermedio, conocido como "piso de la laurisilva", y donde además crece la Myrica faya (faya) y la Erica arbórea (brezo). De esta zona, y de estas especies, proceden, tradicionalmente, las varas, estacas, postes y horcones que se siguen utilizando en la precaria tecnología agrícola de las medianías de la isla. La relación y vecindad de esta cobertura vegetal con la comarca de Gáldar (de donde procede la serie de sellos lignarios documentados en este artículo), facilita esta interdependencia. Relictos florales como Los Tiles o El Brezal, actuales reliquias del otrora famoso Bosque de Doramas (y que persistió en su estado selvático hasta que se procedió a su roturación en el siglo XVIII), testimonian esta posibilidad. No tiene nada extraño que una cultura que reviste sus palacios con tablones de tea (Palacio de Gáldar), excava sus sarcófagos en troncos de pino (cajón funerario de Agaete), fabrica cierres y puertas de madera (Cuevas de Valerón), y dispone sus entablamentos con vigas de tea (Valle de Guayedra, Altabaca) utilice la madera para la fabricación de este mobiliario y, en consecuencia, para grabar sus marcas de propiedad o de identificación. Bien en sus escudos o rodelas, bien en sus sellos pintaderas.

El esmero con que están realizados los motivos - rehundidos con técnica excisa similar a la de la cerámica- advierten la necesidad de un instrumental cortante bien activo. No hace falta, necesariamente, recurrir a hojas o estiletes de metal para obtener estos bellos resultados; aunque nada se opone a su conocimiento y uso por parte de los antiguos canarios. Estos, a partir de sus contactos europeos, incorporan a sus repertorios ergológicos nuevos útiles de importación, extremos estos documentados también en cerámica a torno o esporádicos cortadores de vidrio (ambos elementos certificados en Valle de Guayedra). Las mismas láminas de obsidiana, pasta vítrea volcánica, facilita y tolera unos filos activos muy cortantes y que pueden intervenir superficies lignarias semiduras sin ninguna dificultad. Estas obsidianas laminadas, o lascadas, eran conocidas por los antiguos canarios con el nombre de tausas e, igualmente, se documentan en asociación arqueológica con la Cultura de la Cueva Pintada.

Nada hay, pues, en la materia prima ni en los procedimientos técnicos que se oponga a la realización de estos sellos de madera por los canarios prehistóricos. 


\section{Regiatro de los sellos}

Número 316: $73 \times 37 \times 13 \mathrm{~mm}$. Pedúnculo. Técnica excisa. Semicircular.

Número 708: $19 \times 64 \times 20 \mathrm{~mm}$. Técnica excisa. Circular.

Número 745: $21 \times 17 \mathrm{~mm}$. Técnica excisa. Circular.

Número 746: $25 \times 16 \times 48 \mathrm{~mm}$. Técnica excisa. Circular. Guarda gran analogía con la pieza 36. 2. 659 de El Baal, en Aurés (Onrubia, 1986: 286 y 291).

Número 747: $29 \times 21 \times 68 \mathrm{~mm}$. Técnica excisa. Circular.

Número 755: $35 \times 33 \mathrm{~mm}$. Técnica incisa. Circular.

Número 763: $35 \times 11 \times 23 \times 14 \mathrm{~mm}$. Técnica excisa. Circular. Pedúnculo.

Número 771: $40 \times 18 \times 5 \mathrm{~mm}$. Apéndice $23 \times 30 \mathrm{~mm}$. Excisa. Circular. Pedúnculo.

Número 772: $28 \times 20 \mathrm{~mm}$. Apéndice $49 \times 8 \mathrm{~mm}$. Excisa. Circular. Gran pedúnculo.

Número 775: $270 \times 240 \times 17 \mathrm{~mm}$. Excisa. Cúbico-cuadrangular.

Número 776: $34 \times 18 \times 33 \mathrm{~mm}$. Excisa. Circular. Huellas de fuego.

Número 784: $30 \mathrm{~mm}$. Incisa profunda. Circular.

Número 785: $28 \times 8 \times 63 \mathrm{~mm}$. Excisa. Circular.

Número 793: $33 \times 15 \mathrm{~mm}$. Apéndice $30 \times 29 \times 7 \mathrm{~mm}$. Alto relieve. Circular. Pedúnculo.

Número 794: $31 \times 22 \mathrm{~mm}$. Apéndice 24. Alto relieve. Circular. Pedúnculo con perforación. Excelente estado de conservación. Motivo floral tetráfilo.

Número 802: $30 \times 30 \times 50 \mathrm{~mm}$. Excisa. Circular y cordiforme. Doble impronta. El motivo cordiforme extraño en el registro arqueológico grancanario. Similar a otros sellos auresianos (Onrubia, 1986, Lám. III).

Número 803: $26 \times 26 \times 66 \mathrm{~mm}$. Alto relieve. Circular.

\section{BIBLIOGRAFIA}

Alcon Franch, J. (1956): «Las pintaderas de Canarias y sus posibles relacionesw. Anuario de Estudios Atlánticos, 2: 77-107. Madrid-Las Palmas.

Alvarez Delgado, J. (1942): «Apostillas. El verdadero destino de las "pintaderas" de Canariasw. Revista de Historia, VII: 123-125. La Laguna.

BALOUt, L. (1971): “Canarias y Africa en los tiempos prehistóricos y protohistóricos». Anuario de Estudios Atlánticos, 15: 133-145. Madrid-Las Palmas.

CADAMOSTO. (1895): Relation des voyades a la cote occidentale d'Afrique. Ed. Charles Schefer. Leroux.

CANARIEN, LE (ed. 1980): Crónicas francesas de la Conquista de Canarias. Introducción y traducción de A. Cioranescu. Aula de Cultura. $216 \mathrm{pp}$. La Laguna. Tenerife.

Despors, J. (1953): «Greniers fortifiés de l'Afrique du Nord». Les Cahiers de Tunisie, 1: 38-58. Tunis.

Faublée.Urbain, M. (1951): «Magasins colectifs de l'Oued el Abiod (Aurés)». Journal de la Societé des Africanistes, XXI: 139-160. París.

Grau-Bassas, V. (1881): «Nuevos objetos canarios». El Museo Canario, II, III, 36: 357-360. Las Palmas.

Hooton, E A. (1925): "The ancient inhabitants of the Canary Island». Harvard African Studies, VII. Cambridge, Peabody Museum of Harvard University, $401 \mathrm{pp}$.

Martín de Guzman, C. (1984): Las Culturas Prehistóricas de Gran Canaria. Ed. Excmo. Cabildo Insular de Gran Canaria. Madrid-Las Palmas. 822 pp.

- (1984): «Las fuentes etnohistóricas». Las Culturas Prehistóricas de Gran Canaria, 4: 133-228. Madrid-Las Palmas.

MONOD, TH. (1944): «Sobre algunas pintaderas oeste-africanas». Ampurias, VI: 265-269. Barcelona.

MmLares TORRes, A. (1893): Historia General de las Islas Canarias. I. 278 pp. y II, 319 pp. Imp. I. Miranda. Las Palmas.

Mornles PADró, F. (1978): Canarias: Crónicas de su Conquista. Transcripción, estudio, notas. Ed. El Museo Canario. Sevilla. $536 \mathrm{pp}$.

ONRUBia Pintado, J. (1986): «Sellos y marcas de propiedad de graneros fortificados de Aurés (Argelia). Consideraciones etnoarqueológicas en torno a las presuntas correlaciones norteafricanas de las pintaderas de Gran Canariax. Trabajos de Prehistoria, 43: 281-307. Madrid.

PeLLCER, M. (1974): «Elementos culturales de la prehistoria canaria. (Ensayo sobre los orígenes y cronología de las culturas)y. Miscelánea Arqueológica, II: 145-161. Instituto de Prehistória y Arqueología. Barcelona.

PéreZ de BARRAdAS, J. (1939): «Estado actual de las investigaciones prehistóricas sobre Canarias». El Museo Canario. Tip. Diario. Las Palmas. 35 pp. 
- (1944): «Catálogo de la colección de cerámica y objetos arqueológicos». El Museo Canario, 9. 68 pp. Las Palmas.

Pericot, L. (1955): «Algunos nuevos aspectos de los problemas de la prehistoria canarian. Anuario de Estudios Atlánticos, 1: 579-620. Madrid-Las Palmas.

RIPOCHE, D. (1902): "Les pintaderas d'Europe, des Canaries et de l'Amérique*. Compte rendu du Congrés International des Americanistes, 11 pp. Paris.

SeRRA RAFOLS, E. (1945): «Notas bibliográficas. Dr. Pedro Hernández: Vindicación de nuestras pintaderas. Th. Mond: Sobre algunas pintaderas oeste africanas». Revista de Historia, XI, 70: 239-241. La Laguna.

- (1958): "Bibliografía. Recensión de "Las pintaderas de Canarias y sus posibles correlaciones", de J. Alcina Franchw. Revista de Historia, XXIV: 361-363. La Laguna.

VerneAu, R. (1883): «Las pintaderas de Gran Canaria*. Anales de la Sociedad Española de Historia Natural, XII, $21 \mathrm{pp}$. Madrid. 

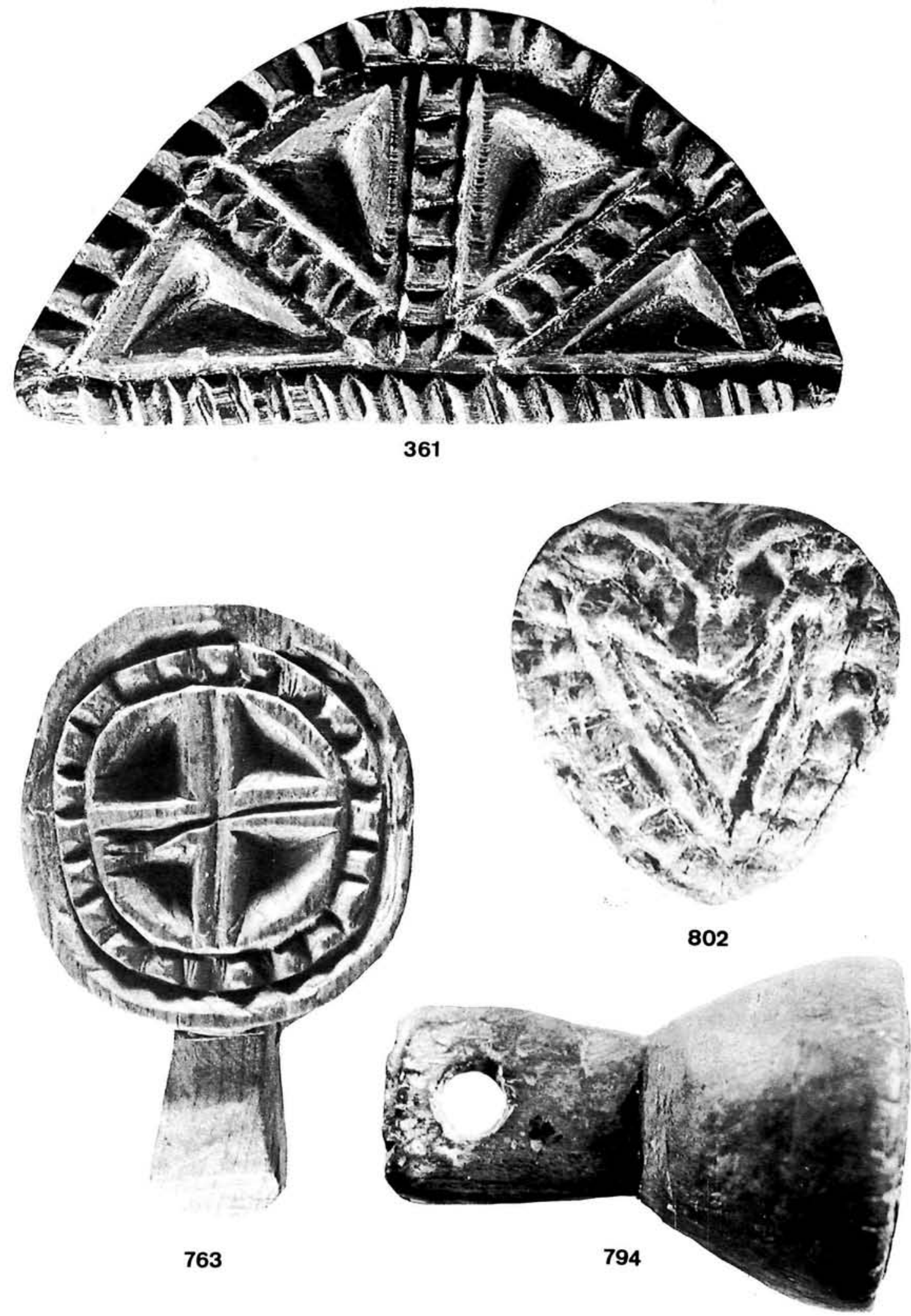

Sellos de madera de Gáldar, números 361, 802, 763 y 794 que se conservan en el Museo Canario de Las Pálmas. 


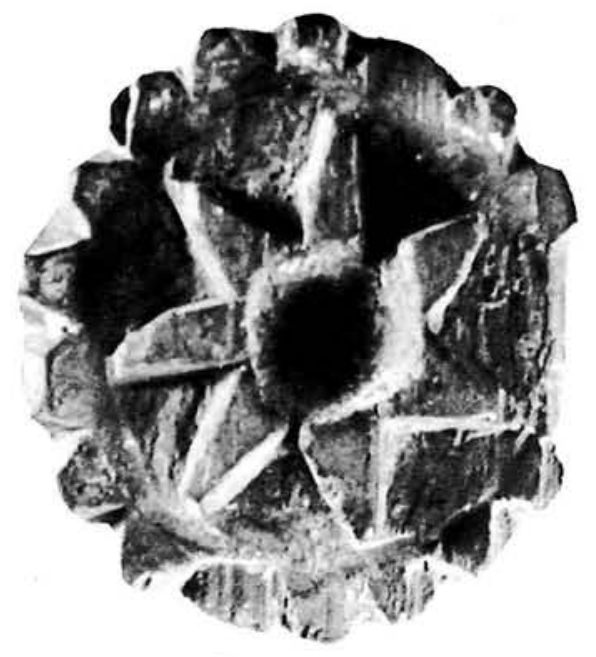

793

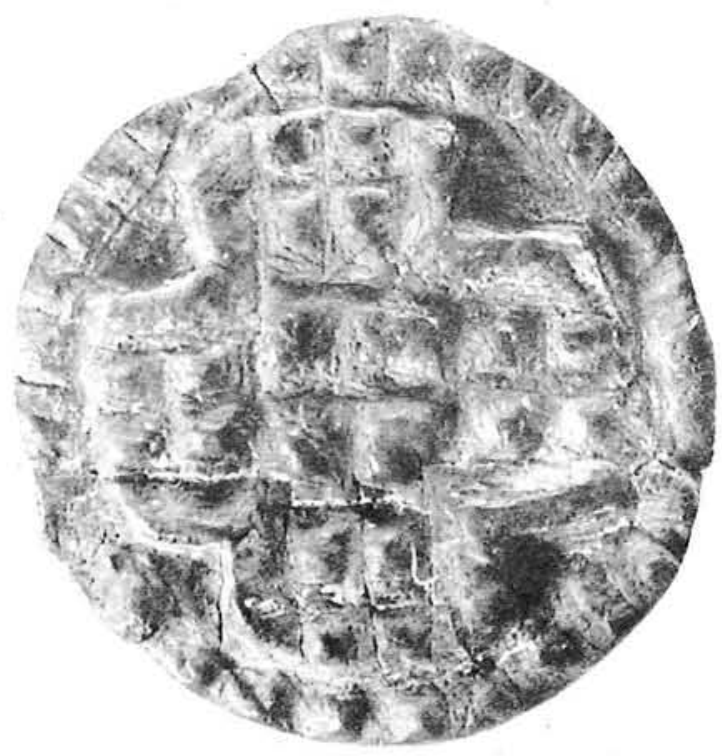

802

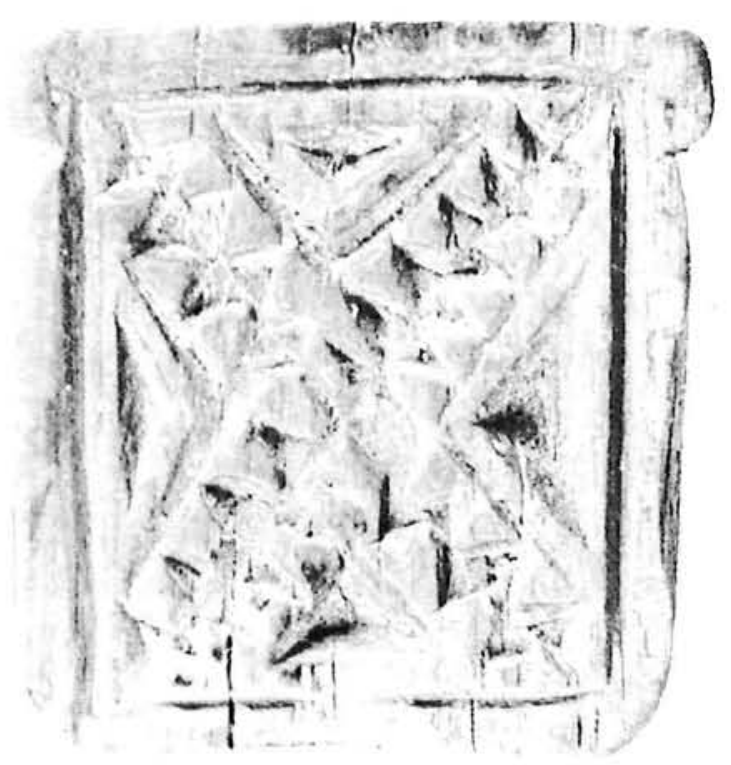

755

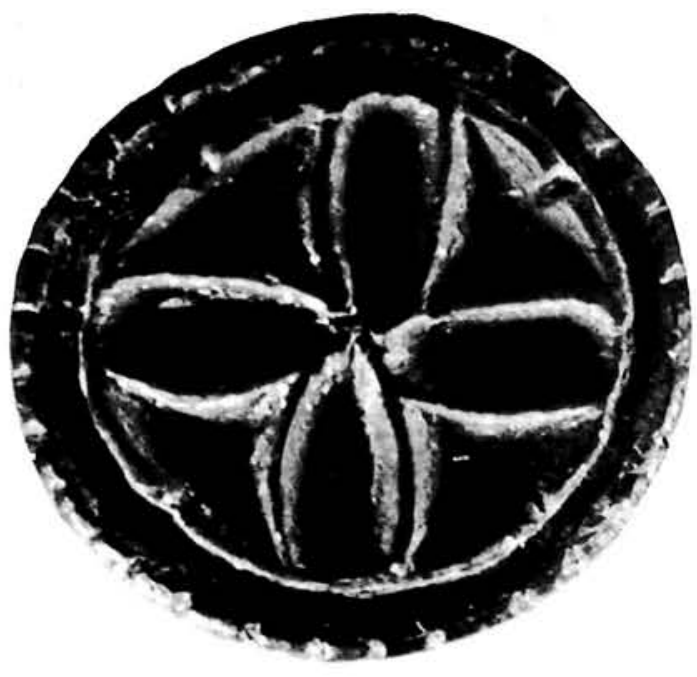

794

Sellos de madera de Gáldar, números 794, 795, 802 y 754 que se conservan en el Museo Canario de Las Palmas. 